\title{
O TEMPO E O ESPAÇO DA \\ SOCIEDADE DA INFORMAÇÃO NO BRASIL'
}

\author{
Aldo de A. Barreto
}

\section{Resumo}

Sociedade da Informação, na definição aqui empregada, é o espaço em que se torna universal o acesso aos conteúdos. Ao pleitear sua entrada na sociedade da informação, o país deverá levar em conta a questão da informação com identidade cultural, privilegiando conteúdos nas várias manifestações de identidade e de modo especial, não incorrer no equívoco de privilegiar apenas informação relacionada às formas de identidade definidas pelo culto da memória ou das origens; tão importante como a identidade vinculada ao passado é a identidade que se projeta para o futuro. Sem dúvida a Ciência da informação precisa se inserir prática e conceitualmente, no esforço de uma Sociedade da Informação para o Brasil. Esta sociedade da informação gerou um documento verde, ainda não maduro e este documento, se observado com atenção, está direcionado mais para explicar e fornecer subsídios tecnológicos de suporte à oferta de informação.

\section{Palavras-Chave}

Ciência da Informação; Sociedade da Informação no Brasil; Tecnologias da Informação; Gestão da Informação

\footnotetext{
${ }^{1}$ Conferência inaugural do "Seminário em Ciências da Informação", promovido pelo Departamento de Ciência da Informação da Universidade Estadual de Londrina, 23 a 25 de agosto de 2001.
} 
Sociedade da Informação em minha definição é o espaço em que se torna universal o acesso aos conteúdos de informação dos estoques de documentos, para todos os habitantes de uma realidade. Esta condição só se realiza quando os possíveis beneficiários deste contexto informacional podem elaborar esta informação, em proveito próprio e para o seu desenvolvimento e desenvolvimento da realidade, onde partilham sua odisséia individual de cidadania. A problemática da sociedade da informação traz um discurso moderno escondendo muitas vezes ou colocando como envelhecidos fatos latentes existentes na realidade como: diferenças de renda, educação, habitação, alimentação, lazer, etc..

Porém, a velocidade de acesso à informação através dos novos meios que revogam as condições estabelecidas de distância e tempo, não tem incidido na cultura ou favorecido as identidades nacionais. ${ }^{2}$ Esse quadro relativo à identidade cultural não se manifesta apenas no chamado mundo subdesenvolvido ou em desenvolvimento. Países do primeiro mundo vêem na preservação da identidade nacional o instrumento decisivo para a autocapacitação não apenas em assuntos culturais como científicos e tecnológicos, com suas claras dimensões econômicas.

\footnotetext{
2 Toda esta inserção sobre identidades culturais é fruto de documento apresentado por Jose Teixeira Coelho No Grupo de Trabalho de Conteúdos e Identidade Cultural do Livro Verde.
}

Medidas de exceção são formuladas para proteger a cultura local em suas mais variadas formas e, mais que isso, é resguardado o próprio idioma nacional, que condensa uma visão de mundo específica - supostamente mais adequada a dar conta de um determinado modo de vida, com seus valores e significados.

Assim, no momento em que o Brasil cuida de criar as condições para sua plena inserção na nova sociedade da informação, é vital que se estabeleça uma política que não se preocupe apenas com a questão econômica e tecnológica dos meios eletrônicos, em particular a Internet, mas que se volte também para os interesses das identidades culturais do país, e seus conteúdos específicos.

Levando em consideração, portanto, que será necessário planejar as ações que conduzem à produção e distribuição de conteúdos que sirvam aos interesses do país, e entendendo por identidade cultural a soma de significados que estruturem a vida de um indivíduo ou de um povo, partese do princípio de que será necessário ter em mente, antes de tudo, que a identidade cultural não é una, mas múltipla; deverá levar em conta a questão da identidade cultural nas suas várias manifestações e de modo especial, não incorrer no equívoco de privilegiar apenas as formas identitárias definidas pelo culto da memória ou das 
origens; tão importante como a identidade vinculada ao passado é a identidade que se projeta para o futuro.

Com qualquer conteúdo, porém, se existe uma promessa que, a sociedade de informação permitirá o acesso de todos, igualmente, à informação da internet, isso satisfaz o nosso intrincado sentimento colonizado que, almeja sempre um estar por perto do primeiro mundo.

As mudanças na tecnologia da informação ocorridas durante os últimos anos, reorganizaram todas as atividades associadas à ciência da informação. No curto prazo, a sociedade sempre foi mais afetada pelas transformações, ou pela natureza, da tecnologia do que pelo seu conteúdo. Aqueles que convivem mais de perto com estas agitações enfrentam com maior carga às conseqüências sociais e físicas de uma enorme ansiedade tecnológica.

O profissional desta área foi precipitado em uma conjunção de transformações, muitas das quais ele, ainda, nem mesmo se apercebeu. Durante um período de inovação o contexto em mudança se torna quase invisível e melhor aparece para análise, quando é substituído pelo outro, daí ser bem mais fácil entender hoje, a sociedade industrial do que a sociedade de informação.

O modelo tecnológico inovador é tão fechado que induz a um distanciamento alienante de como ele opera ou se opera no melhor sentido. Se o discurso da Sociedade de Informação traz não só uma premissa técnica, mas também, uma promessa de verdade, traz consigo uma esperança de melhoria das condições do homem, de conforto material e de felicidade.

Este é um discurso imbatível. No caso das tecnologias de informação, se a promessa é promover o acesso universal à informação, à educação, a melhores oportunidades de emprego e ingresso ao entretenimento, e se esta é uma promessa da autoridade tecnológica constituída, o conhecimento que envolve a promessa, já está fechado e avaliado. Não é passível de dúvida ou contraposição sob pena de nos colocarmos contra o avanço tecnológico, retrógrados e ultrapassados e até pouco éticos em relação ao bem estar geral.

A autoridade tecnológica julga e condena quem quer se inserir no conhecimento dos detalhamentos dos seus processos. Não cabe questionar ou tentar compreender como uma informação é transmitida através dos backbones ${ }^{3}$ da infraestrutura de transferência da informação. Este conhecimento, para os usuários, é em si irrelevante e até mesmo indesejável.

Se as promessas das conseqüências da tecnologia são benéficas para a socie-

\footnotetext{
3 Backbones - "Espinha dorsal" de uma rede; ligações, interligações e sub-enlaces dos espaços por onde passará a rede, o acesso enfim.
} 
dade, questionar é pouco decente, do ponto de vista do questionado é claro.

Mas, a crise que, ocorre com a ciência da informação, neste devir do novo século, deve ser computada lembrando sua evolução na história que esta área já possui.

Falar da sociedade de informação no Brasil nos leva inevitavelmente a refletir sobre a oferta, a demanda e a mercadoria informação. Não se pode pensar o fluxo da mercadoria sem conhecer a mercadoria em si. Isto é, eu não posso resolver o problema da informação, através de um excelente processo de transferência. As qualidades do produto em si independem da qualidade de seu transporte. Embora o transporte vá influenciar na satisfação do usuário.

Assim, a mercadoria que determina este mercado, a informação, é uma mercadoria simbólica, ${ }^{4}$ de características muito especiais. É uma mercadoria que não se esgota com o consumo como uma maçã ou um copo de leite. Ao ser consumida a mercadoria, ainda, permanecerá consumível, por um tempo e em um espaço, determinado por sua qualidade e validade.

\footnotetext{
${ }^{4}$ Simbólica: O uso da palavra articulada ou escrita como meio de expressão e de comunicação entre pessoas; a forma de expressão pelas diferentes linguagens de que pode se utilizar um indivíduo, grupo, classe, etc.
}

Ainda, ao ser consumida, um consumidor não tem a propriedade única da mercadoria; ela continua como propriedade de quem a vendeu ou a repassou, e que a venderá quantas vezes quiser, salvo em casos muito especiais quando um contrato é firmado para determinada informação específica. Apesar de ter a sua posse, o consumidor só poderá dela se apropriar se tiver competências pessoais para tanto; a posse da mercadoria informação é subjetiva. $^{5}$

A mercadoria informação não é escassa, é abundante, mas é esta abundância que the confere as características da escassez, pois só tem um valor para o consumidor a informação que, ao lhe ser disponibilizada é potencialmente útil, relevante. A contextualização da informação abundante lhe confere valor.

Sua unidade de medida é imprecisa quando não é associada a uma base fixa, e a mercadoria não é homogênea como quilos de batata, litros de leite ou canetas Bic.

Seu preço, quando esta o possui, pouco tem a ver com o seu custo, e os dois, preço e custo, não se relacionam com o valor como uma mercadoria tradicional, e muito menos com as condições de oferta e demanda que determinariam o mercado de informação.

\footnotetext{
5 Relaciona-se ao sujeito do consumo e não ao objeto consumido.
} 
É esta mercadoria que acabamos de descrever, que o discurso da sociedade da informação chama de "conteúdos"; e é com esta mercadoria que tem que operar a sociedade da informação, pois esta sociedade só se viabiliza se os seus habitantes se articularem com a prática e a troca deste produto simbólico, abrindo uma condição de oferta e demanda desta mercadoria informação.

É razoavelmente fácil determinar os números da oferta de informação, principalmente em termos quantitativos e sobretudo, aqueles dados, relacionados com a quantidade de recursos destinados a prover a oferta.

Já as condições da demanda se ocultam. Os dados da necessidade de informação e o potencial das competências individuais para sua apropriação são difíceis de delimitar. A demanda se entrelaça com os desejos humanos, subjetivos, escondidos.

Daí o entusiasmo da Sociedade da Informação e da ciência da informação, ao tratarem sempre com maior constância e conforto da gestão da informação, quando esta se processa no lado da oferta de informação, no agenciamento dos estoques de informação, na administração dos acervos.

Assim, a gestão da informação pode ser tão autoritária quanto as políticas e os documentos que a orientam. A figura 1 , ilustra uma gestão da informação orientada para a oferta: a seta 1 indica o consumo real de informação, que se utiliza somente de uma parte do estoque da oferta, para uma demanda limitada na realidade. Aqui se subentende que é a oferta que está comandando a demanda por informação, pois ela tem este poder.

A seta 2 pretende indicar uma tentativa de administrar uma oferta secundária, universalizar o acesso, repassando o estoque excedente para os demais espaços de uma realidade fragmentada em suas competências de apropriação, desnutrida de cidadania e com oportunidades diferenciadas. Uma enorme dívida social está como pano de fundo de tudo isso. 


\section{Figura 1}

\section{A GESTÃO DA INFORMAÇĀO}

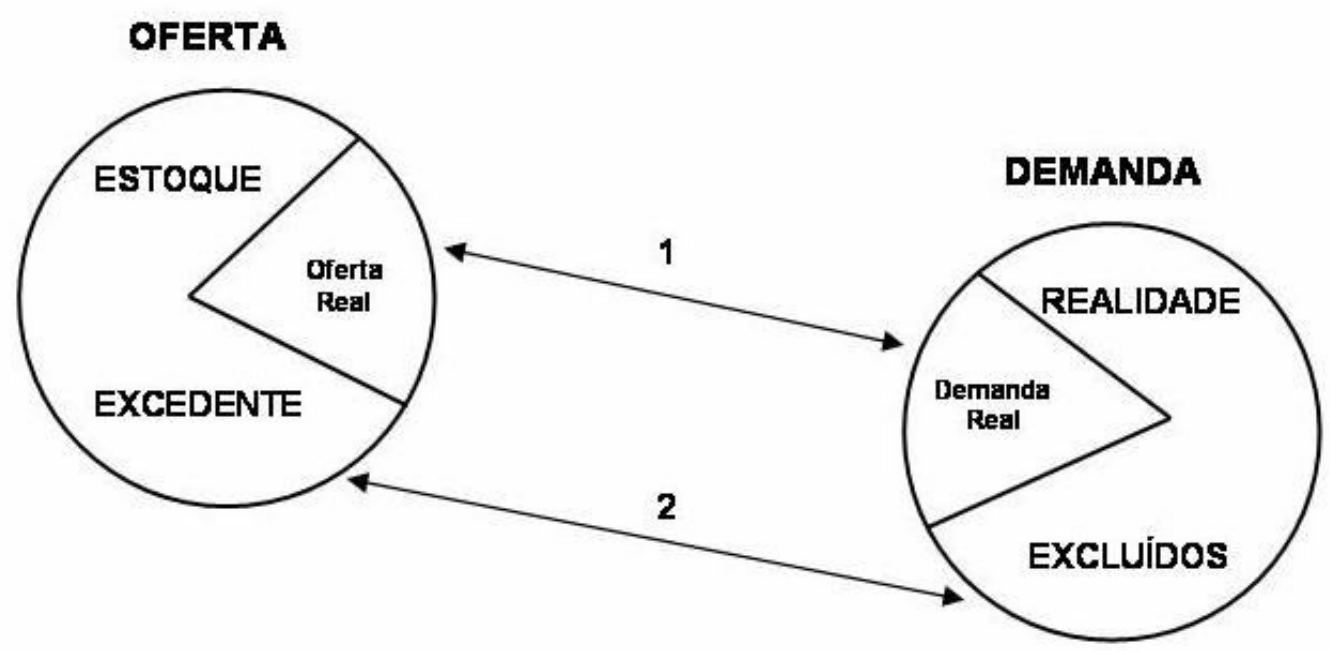

A ciência da informação e a sociedade da informação atuam no menor setor da figura anterior. A apropriação da informação envolve uma série de fatores que, estão fora da competência ou governabilidade, tanto da ciência da informação como da sociedade da informação, resolver. Mais é necessário saber em que realidade se pretende estabelecer uma sociedade com informação, sob pena de se estar operacionalizando mais um country club da informação.

Sem dúvida, a ciência da informação precisa estar inserida no esforço de uma Sociedade da Informação no Brasil. Esta sociedade da informação gerou um documento verde ainda não maduro (TAKAHASHI, 2000). Este documento, se observado com atenção, está direcionado, prioritariamente, para explicar e fornecer subsídios tecnológicos de suporte para a oferta de informação, uma condição que já tratamos anteriormente neste texto.

O Livro Verde é um documento correto que, contou com a colaboração de inúmeros cientistas e especialistas. Foi idealizado e realizado com muita criatividade, dedicação e respeito aos seus propósitos; mas é também, um documento indispensável para a biblioteca de uma aliança globalizada.

Deixa claro que induz a ações de parceria: na página 11 , capitulo 1 da versão 1 do documento impresso (TAKAHASHI, 2000), fica estabelecido: ao governo cabem os "backbones" para universalização do acesso e algumas aplicações próprias de Estado; a sociedade cabe viabilizar e articular os conteúdos e as suas aplicações de interesse específico; mas o investimento em, fornecer produtos e serviços, ter a necessidade de manter uma con- 
tinua densidade tecnologia em inovações intensas, esta deve ser uma tarefa do setor privado. Nesse último caso seria um erro de cálculo o Governo competir neste mercado intensamente povoado de condições materias e de recursos humanos caros e exclusivos; de tecnologias com pesados investimentos e mutáveis sempre no curto prazo. Isto pode criar uma necessidade de ressarcir investimentos e um intenso desejo e necessidade de colocar um preço na mercadoria contrariando o sonho do livre fluxo de informação.

Há que considerar ainda, que o programa sociedade da informação se localiza em um dos ministérios do governo e por estar neste nível hierárquico, o programa não traz uma força política que facilite sua implantação, ou mesmo um sentido para inserção em um planejamento global. Todo governo é sensível a sua graduação da autoridade e aos círculos de predomínio de poder, assim, os setores de comunicações do governo irão lançar as suas próprias bases e seus planos de uma infraestrutura de acesso universal, os setores de educação as suas bases e instrumentos das escolas eletrônicas e interligadas e da educação à distância; a casa civil do governo, já está conduzindo, com suas regras, as bases do governo eletrônico da assinatura digital e a esfera da cultura, anda cuidando, a seu modo, dos conteúdos com identi- dade cultural, das bibliotecas, dos museus e dos arquivos.

O documento da sociedade da informação no Brasil foi válido em sua excelente confecção, nas suas pretensões, intenções e idéias, sobretudo, no desejo e dedicação dos indivíduos, que colaboraram para sua confecção: com respeito, motivação e muita esperança.

O documento, em minha opinião, tinha duas opções: ser abrangente como está e arriscar-se a ser um trabalho de referência ou ser muito específico, por exemplo, tratando só do acesso universal e da informação em ciência e tecnologia, e então correr o risco de não ter uma platéia muito grande e o que é pior, talvez ter que administrar a execução das ações propostas.

Contudo, o plano verde escolheu ser grande e abrangente e perdeu-se na burocracia das intenções de poder de cada setor do Governo. Permanecerá como um excelente documento de referência. Uma diretriz para organizar e induzir ações para uma sociedade mais justa. 


\section{REFERÊNCIAS}

BAQUERO MIGUEL, G. Estudo do Fluxo Escolar do $1^{\circ}$ para o $2^{\circ}$ grau de 1972-1982. MEC/SG/SEEC, 1988.

.; OLIVEIRA, L. A. Ensino Regular de primeiro Grau no Brasil, 1950-1984. MEC/SG/SEEC, 1988.

BARRETO, A. de A. A informação e o Cotidiano Urbano. Rio de Janeiro: IBICT/Eco, 1991.

A informação e a transferência de

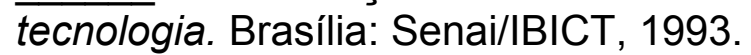

A transferência de informação: o desenvolvimento tecnológico e a produção de conhecimento. Informare, v.1, n.2, jul./dez 1995.

BOULDING, K. Knowledge and life in society. USA: University of Michigan Press, 1960.

BUTCHER, H. J. A inteligência Humana. São Paulo: Perspectiva, 1968.

FARRADANE, J. Knowledge: information and information science. Journal of Information Science. London, v.2, n.2, 1980.

. The nature of information. Journal of Information Science. London, v.1, n.3, 1970.

HABERMAS, J. Conhecimento e Interesse. Rio de Janeiro: Guanabara, 1987.

HUMPHREY, N. Uma Historia da Mente: a evolução e a gênese da Consciência. Rio de Janeiro: Campus, 1994.

INSTITUTO BRASILEIRO DE GEOGRAFIA E ESTATÍSTICA. Anuário Estatístico do Brasil de 1996 a 1999. Centro de Documentação e Disseminação de Informações. Edição em CD-ROM.

Sistema IBGE de Recuperação Automática-SIDRA 1997. Disponível em: <http://www.sidra.ibge.gov.br>. Acesso em: 15 maio 2001.

JAENEKE, P. To what end Knowledge Organization. Knowledge Organization. n.1, p.3-10, 1994.

KING, D. W.; BRYANT, E.C. The evaluation of information services and products. USA: Information Resource Press, 1971.

LAMBERTON, D. M. (Ed.) Economics of information and knowledge. London: Penguin, 1971.

LANCASTER, F. W. The measurement and evaluation of library services. USA: Information Resource Press, 1977.

MINISTÉRIO DE CIÊNCIA E TECNOLOGIA. Indicadores Nacionais de Ciência e Tecnologia. Disponível em: <http://www.mct.gov.br>. Acesso em: 09 jun. 2001.

MORIN, E. O método: o conhecimento do conhecimento. Lisboa: Biblioteca Universitária, 1986.

TAKAHASHI, T. (Org.). Sociedade da Informação no Brasil: livro verde. Brasília: MCT, 2000.

\section{Aldo A. Barreto}

Pesquisador Titular do MCT/lbict e ExPresidente da Associação Nacional de Pesquisa e Pós Graduação e Ciência da Informação - Ancib 


\section{Title}

The time and the space of information society in Brazil

\begin{abstract}
The information Society definition adopted by this work is the space in that the access to information contents becomes universal. While pleading an entrance in the information society, Brazil should take into account the information contents, with cultural identity, privileging contents in its several identity manifestations and, in a special way, should not to incur in the misunderstanding of just privileging information related to identity forms defined by the cult of the memory or by its origins; because as important as the identity connected to the past it is the identity that is projected for the future. There is no doubt that the Information Science needs to insert itself in a practical and in a conceptual way to get into the effort for the development of an Information Society in Brazil. The Information Society study generated a green document, one not already mature, and this document, if observed with attention, is addressed much more to explain and to supply technological subsidies of support for the information offering.
\end{abstract}

\section{Keywords}

Information Science; Information Society in Brazil; Information Technology, Information Management

\section{Titulo}

El tiempo y el espacio de la sociedad de la información en Brasil

\section{Resumen}

Sociedad de la Información, en la definición aquí puesta, es el espacio en que se torna universal el acceso a los contenidos. Al pleitear (alegar) su entrada en la sociedad de la información, el país deberá llevar a cabo la cuestión de la información con, identidad cultural, privilegiando contenidos en las varias manifestaciones de identidad y de modo especial, no incorrer (transcurrir) en el equívoco de privilegiar a penas información relacionada a las formas de identidad definidas por el culto de la memoria o de los orígenes; tan importante como la identidad vinculada al pasado es la identidad que se proyecta para el futuro. Sin duda la Ciencia de la información precisa se inserir práctica y conceitualmente, en el esfuerzo de una Sociedad de la Información para Brasil. Esta sociedad de la información generó un documento verde, todavía no maduro y este documento, se observado con atención, está direccionado más para explicar y fornecer subsídios tecnológicos de soporte a la oferta de información.

\section{Palabras Clave}

Ciencia de la Información; Sociedad de la Información en Brasil; Tecnologías de la Información; Gestión de la Información

Artigo recebido em: 23/08/2001 